\title{
On Simulation of the Nash Equilibrium in the Stock Exchange Contest
}

\author{
Jonas MOCKUS \\ Vilnius University, Institute of Mathematics and Informatics \\ Akademijos 4, Vilnius, LT-08663, Lithuania \\ e-mail: jmockus@gmail.com
}

Received: December 2009; accepted: March 2011

\begin{abstract}
A simple Stock Exchange Game Model (SEGM) was introduced in Mockus (2003), to simulate the behavior of several stockholders using fixed buying-selling margins at fixed bank yield.

In this paper, an extended model USEGM is proposed. The advantage of USEGM is application of the Nash Equilibrium (NE) to strategies that define buying-selling margins and bank haircuts dynamically. This enables us to simulate market illiquidity that is an important feature of the present financial crisis (Allen, 2008). In addition, USEGM includes the transaction costs to reflect the reality better. To represent users that prefer linear utility functions, USEGM adds the AR-ABS $(p)$ autoregressive model, minimizing the absolute values, to the traditional $\operatorname{AR}(p)$ model minimizing least square deviations.

A formal application of NE to simulate the behavior of market participants is a new feature of these models. In the well-known works Allen (2008), Brunnermeier (2009), Brunnermeier and Yogo (2009) equilibrium ideas were applied to supply-demand balance concepts, as usual.

The objective of USEGM is not forecasting, but simulation of financial time series that are affected by predictions of the participants. The "virtual" stock exchange can help in testing the assumption of rational investor behavior vs the recent theories that explain financial markets by irrational responses of major market participants (Krugman, 2000, 2008, 2009). The model helps comparing expected profits of different prediction models using the virtual and historical data.

The model has been compared with eighteen actual financial time series and found the results to be close in many cases.
\end{abstract}

Keywords: optimization, nash equilibrium, stock exchange, time series, efficient market.

\section{Introduction}

\subsection{Market Description}

There are many important investigations of financial crises including extraordinary events in 2007 and 2008 (Allen and Gale, 2007; Allen, 2008; Brunnermeier, 2009; Darley and Outkin, 2007). A detailed formal description of these processes and their interactions is not practical, therefore the authors of these papers present the research results in general terms with references to real-life data, as usual (Allen and Gale, 2007; Bernanke, 2005, 1983; Krugman, 2000, 2008, 2009; Greenspan, 2009). 
The first analysis of the Great Depression is made in Keynes $(1936,2007)$ using the general terms. Describing some specific features of the market process, mathematical expressions were applied in many publications. In Brunnermeier (2007), the optimal balance of pessimistic-optimistic beliefs and asset prices is regarded in a formal way. In Brunnermeier (2003), a model is presented in which an asset bubble can persist despite the presence of rational arbitrageurs. In Brunnermeier (2004), theoretical results are applied in explaining the relations of hedge funds and the technology bubble.

The paper Brunnermeier et al. (2008) documents that 'carry traders' are subject to the crash risk. The term 'carry trade' without further modification refers to currency 'carry trade': investors borrow low-yielding and lend high-yielding currencies. It tends to correlate with the global financial and exchange rate stability, and retracts in use during global liquidity shortages.

The paper Brunnermeier (2009) summarizes and explains the main events of the liquidity and credit crunch in 2007-2008, starting with the trends leading up to the crisis. The paper explains by real data how these events unfolded and how different amplification mechanisms magnified losses in the mortgage market into large dislocations and turmoil in financial markets.

In Brunnermeier and Pedersen (2007), the authors provide a model that links an assets market liquidity, i.e., the ease with which it is traded, and traders' funding liquidity, i.e., the ease with which they can obtain funding. Traders provide the market liquidity, and their ability to do so depends on their availability of funding. Conversely, traders' funding, i.e., their capital and the margins they are charged, depend on the assets market liquidity. The paper shows that, under certain conditions, margins are destabilizing while the market liquidity and funding liquidity are mutually reinforcing, leading to liquidity spirals. The model explains the empirically documented features that the market liquidity can suddenly dry up.

The paper Brunnermeier and Julliard (2006) describes a formal model explaining how a reduction in inflation can fuel run-ups in housing prices, if people suffer from money illusion. For example, investors, who decide whether to rent or buy a house by simply comparing monthly rent and mortgage payments do not take into account that inflation lowers future real mortgage costs. The authors decompose the price-rent ratio in a rational component (meant to capture the proxy effect and risk premium) and an implied mispricing. They find that inflation and nominal interest rates explain a large share of the time-series variation of mispricing, and that the tilt effect is unlikely to rationalize this finding.

The paper Brunnermeier (2007) studies portfolio holdings and asset prices in an economy in which people's natural tendency to be optimistic about the payout from their investments is tempered by the expected losses of basing their portfolio decisions on incorrect beliefs. The authors show that this model can generate the following three facts. First, household portfolios are not optimally diversified. Second, household portfolios are tilted toward stocks with identifiable attributes. Third, positively skewed assets tend to have lower returns. The paper argues that these three patterns are observed because human beings want to believe what makes them happy and want to make good decisions that lead to good outcomes in the future. 
The paper Brunnermeier and Yogo (2009) shows by examples that, when a company is unable to rollover its debt, it may have to seek more expensive sources of financing or even liquidate its assets. This paper provides a normative analysis of minimizing a rollover risk through the optimal dynamic choice of the maturity structure of debt. The objective of a company with long-term assets is to maximize the effective maturity of its liabilities across several refinancing cycles, rather than to maximize the maturity of the current bonds outstanding. An advantage of short-term financing is that a firm, while in good financial health, can readjust its maturity structure more quickly in response to changes in its asset value.

In Brunnermeier and Nagel (2006), data from the Panel Study of Income Dynamics (PSID) was used to investigate how households' portfolio allocations change in response to wealth fluctuations. The theoretical model indicates that persistent habits, consumption commitments, and subsistence levels can generate time-varying risk aversion with the consequence that when the level of liquid wealth changes, the portion a household invests in risky assets should also change in the same direction. In contrast, the data analysis shows that the share of liquid assets that households invest in risky assets is not affected by wealth changes. Instead, one of the major drivers of households' portfolio allocation seems to be inertia: households re-balance only very slowly following inflows and outflows or capital gains and losses.

\subsection{Market Prediction}

Different individuals may regard the market prediction problem differently. Therefore, providing research tools to interested parties, such as graduate students in relevant fields, may contribute to further understanding of these markets. The USEGM model can be regarded as one of such tools.

The market prediction task divides researchers into two groups: those who believe that we can devise mechanisms for predicting the market, and those who believe that the market is efficient and, whenever any new information appears, the market absorbs it by correcting itself. A convenient mathematical tool representing the latter model is the Wiener process, which implies that the best possible prediction of the next value is based only on the present value (Fama, 1995; Plagge, 2007). The Wiener model is often called the Random Walk (RW).

In this paper, a non-traditional game-theoretical explanation of the RW is proposed as a hypothesis. The stock exchange is regarded as a game of competing players trying to maximize the wins by selling assets ${ }^{1}$ at high prices and buying them at lower prices. Selling-buying levels are based on next-day ${ }^{2}$ predictions by autoregressive models $\operatorname{AR}(p)$ or $\operatorname{AR}-\operatorname{ABS}(p)$ of order $p$. The difference is that, while determining the parameters in AR$\operatorname{ABS}(p)$, an absolute deviation is minimized instead of the least square one. The AR-ABS model follows from the assumption that players are risk neutral, which means that utility

\footnotetext{
${ }^{1}$ The term assets means any assets of financial market, for example, stocks, futures, bonds, loans, etc.

${ }^{2}$ The term 'next-day' means next time unit, for short.
} 
functions are linear. The AR model represents risk-aversion by overestimating relative importance of large losses.

In real life, the asset holders predict by their own specific models. We consider the autoregressive models as a reasonable first approximation of such forecasting strategies.

In USEGM players control the order $p$ of the autoregressive models directly or by some mixed strategy $x$ that defines probabilities of $p$. Margins of individual investors and haircuts of banks are defined by linear functions of the estimated risk, depending on the previous losses. Players make profit if they predict correctly.

It is unlikely that the USEGM provides a complete description of the behavior of stock market participants. For example, ordinary stockholders ${ }^{3}$ are not trying to achieve the equilibrium, they are just looking for a greater profit. However, the model may be useful in explaining prediction peculiarities of financial time series, where the prices are affected by predictions of market participants. The model represents, in a simple gametheoretical form, some basic arguments of the efficient market theory and, therefore, is a natural initial approximation. Thus, RW can be regarded as a benchmark of minimal efficiency convenient for evaluating more sophisticated prediction techniques. We regard the results and tools, described in this paper, as an example encouraging a further research along similar lines by interested persons, not just by professional investors.

To compare the simulation results with real data, the RW model was tested using financial time series of eighteen assets. Five simulated time series were taken for comparison. The Amazon river discharge and the demand rate in a call center were regarded, too, to illustrate the difference between financial, physical, and commercial data.

To reflect risk-neutral users, the Autoregressive by Absolute Values $\operatorname{AR}-\operatorname{ABS}(p)$ model of order $p$ was used. The parameter $p$ was optimized for each asset. The RW $(p=1)$ provided the best results for cocoa futures prices and for the simulated Wiener process. In other cases, the results of RW were not optimal, but close.

\subsection{Market Simulation}

The research Allen (2008) shows that the present crisis is connected with market illiquidity. Simulation of the complete crisis process is too difficult. Therefore, it is of interest to create simple models that explain at least some of the interesting properties of financial and related markets.

A common feature is that future financial data depend on predictions. Another common feature is the balance of conflicting interests. The game-theoretical concept for that is Nash Equilibrium (NE) (Nash, 1951; Debreu, 1982). In simple terms, NE can be defined as a contract of players that provides no incentives to brake it. It means that no player can get additional profit by breaking NE. In this paper, a NE based model, reflecting both predictions and balance of interests is proposed, implemented, and investigated. We refer to it as an Updated Stock Exchange Game Model (USEGM).

In the previous game models SEGM (Mockus, 2003, 2010; Mockus and Raudys, 2010) the behavior of several individual investors was considered assuming that they

\footnotetext{
${ }^{3}$ The term stockholder means a holder of financial asset, for short.
} 
are buying-selling stocks in accordance with NE at fixed buying-selling levels defined by $\operatorname{AR}(p)$ predictions. The proposed USEGM model considers, in addition, the equilibrium behavior of banks that finance individual investors, too. When defining the buying-selling levels, the transaction costs are included. The risk neutral behavior of investors is reflected by using the AR-ABS $(p)$ predictions. All these new features of USEGM eliminate some important disadvantages of the SEGM model and represent financial markets better. The novelty of both SEGM and USEGM models is a direct simulation of the behavior of financial operators in the context of NE.

Another approach was applied in Darley and Outkin (2007), where the NASDAQ market was simulated as an adaptive system. In Ramanauskas and Rutkauskas (2009), an artificial stock market model, based on interaction of heterogeneous agents, is proposed. Ramanauskas and Rutkauskas (2009) use the model for the analysis of market self-regulation abilities and market efficiency.

The idea that the financial market is a "casino" game was expressed in Keynes (1936, 2007). In Krugman (2000, 2008, 2009), the unpredictability of asset prices is explained by the irrational behavior of participants. In the report Greenspan (2009), financial crises are explained as the inevitable result of a natural human tendency, namely, the tendency of human beings when confronted with long periods of prosperity to presume that it will continue.

According to the models of this paper the seemingly irrational behavior of market participants can be considered as rational under the specific conditions of decision making and the available information. Looking this way, differences between the efficient market theory (Fama, 1995) that assumes the rational behavior of market players and theories based on the irrational behavior (Krugman, 2000, 2008, 2009) are not so significant.

In the updated model, the Nash Equilibrium (NE) is applied to strategies that define buying-selling margins and bank haircuts dynamically. This enables us to simulate market illiquidity that is an important feature of the present financial crisis (Allen, 2008).

In USEGM investors are using borrowed money for their operations. Linear strategies are applied both to control margins of buying-selling levels of investors and haircuts of banks.

Investor strategies are to define their buying and selling levels for the next iteration via the autoregressive models $\operatorname{AR}(p)$ or $\operatorname{AR}-\operatorname{ABS}(p)$ of order $p$. The order $p$ is set directly or by some mixed strategy $x$ defining the probabilities $x$ of $p$. These strategies and coefficients of the linear margin and haircut strategies are selected by minimizing expected deviations from the Nash Equilibrium (NE).

A formal application of NE to simulate the behavior of market participants is a new feature of the models. In the well-known works Allen (2008), Brunnermeier (2009), Brunnermeier and Yogo (2009) equilibrium ideas were applied to supply-demand balance concepts, as usual.

The objective of USEGM is not forecasting but simulation of financial time series that are affected by predictions of the participants. The "virtual" stock exchange based on NE conditions can help testing the assumption of rational investor behavior vs the recent theories explaining financial markets by irrational responses of major market participants 
(Krugman, 2000, 2008, 2009). The simulation by the Wiener model can be useful for explaining the Random Walk (RW) model of the efficient market theory (Fama, 1995). For example, the simulations by the earlier version SEGM (Mockus, 2003, 2010) suggested that NE was close to the Wiener model.

To compare the simulation results with real data, the model was tested, using eighteen real and five simulated financial time series. The Amazon river discharge and the rate of call center demands were regarded as well to illustrate the difference between financial, physical, and commercial data.

The interactive software is implemented as a Java applet, published in an open website and can be run by any browser with Java support. A version of USEGM, including automatic optimization of buying-selling margins and bank haircuts as functions of the expected risks, is under development.

The proposed financial market models are designed as a tool for simulating the market processes in response to different changes of market parameters. The models helps comparing expected profits of different prediction methods using the virtual and actual historical data, too. Convenient user interactions are provided by implementing the models as a Java applet and publishing it in an open web-site (Mockus, 2007). The updated versions of the model and new experimental results will be presented on these web-sites during the process of USEGM development.

\section{Extended Stock Exchange Game Model (USEGM)}

The purpose of USEGM is to explore the relationship between the real data and Nash equilibrium and to investigate what other results can be obtained using this simple model. For example, a dynamic control of buying-selling margins and bank rate haircuts provides a possibility to simulate the market and fund illiquidity as the cause of financial crisis. The interactive mode of buying-selling levels allows simulation of artificial control of market prices.

The scientific objective of this approach is to test the hypothesis that some important stock exchange features can be approximately described as a game of players using strategies, based on the Nash equilibrium. It is supposed that stock prices are primarily the result of the game of major stockholders with some random deviations that represent large numbers of small investors. Investment decisions depend on stockholders' predictions of the future stock prices and expected dividends. The expected risk defines margins of stockholders and haircuts of banks. This model is used to investigate what could be learned about the basics of market theory using the simple game-theoretical stock exchange model.

USEGM assumes that each player predicts stock prices by the autoregressive models $\operatorname{AR}(p)$ or $\operatorname{AR}-\operatorname{ABS}(p)$ of order $p$. Scale parameters $a(41)$ of the the model $\operatorname{AR}(p)$ are estimated using the standard least squares algorithm (42) for different $p^{4}$. The scale pa-

\footnotetext{
${ }^{4}$ The values of $p$ in the both models are defined using pure or mixed strategies where $p$ is determined by some probability distribution.
} 
rameters $a$ of the $\operatorname{AR}-\operatorname{ABS}(p)$ model which represents linear utility function are defined by the linear programming (46).

Actual stockholders use their own ways of predicting. We regard the $\operatorname{AR}(p)$ and AR$\operatorname{ABS}(p)$ models as the simplest initial approximations of the prediction processes.

In some cases, simulations using $\operatorname{AR}(p)$ models with various $p$ at fixed buying-selling levels indicate that the expected profit cannot be improved by deviation from the Wiener model ( $p=1$ and $a=1$ ). This represents a new explanation of the RW model. The basic formulas of USEGM are as follows. The additional formulas are on the web-sites, for example: http://prof.if.ktu.lt jonas.mockus/igor/stock.pdf. The formal description will be updated and the new experimental results will be presented on these web-sites during the process of USEGM development.

\subsection{Buying and Selling Strategies}

We start a formal description by considering a simple case of $I$ major players $i=1, \ldots, I$ and a single joint-stock company. The following notation is used:

$z(t)=z(t, i)$ is the price at time $t$, predicted by the player $i$,

$Z(t)$ is the actual ${ }^{5}$ price at time $t$,

$U(t)=U(t, i)$ is the actual profit accumulated at time $t$ by player $i$,

$\delta(t)$ is the dividend at time $t$,

$\alpha(t)$ is the yield at time $t$,

$\gamma(t)$ is the interest rate at time $t$,

$h(t)=\gamma(t)-\alpha(t)$ is the haircut ${ }^{6}$,

$\beta(t, i)$ is the relative stock price change at time $t$ as predicted by the player $i$

$$
\beta(t, i)=(z(t+1, i)-Z(t)) / Z(t) .
$$

Expected profitability ${ }^{7}$ (relative profit) $p(t, i)$ of an investment at time $t$ depends on the predicted change of stock prices $\beta_{i}(t)$, dividends $\delta_{i}(t)$, the bank rate $\alpha(t)$, and haircut $h(t)$

$$
p(t, i)=\beta(t, i)-\alpha(t)+\delta(t)-h(t)=\beta(t)+\delta(t)-\gamma(t) .
$$

The aim is profit, thus a customer $i$ will buy some number $n_{b}(t, i) \geqslant n(t)$ of stocks, if profitability is greater comparing with the relative transaction cost $\tau(t) ; p(t, i)>\tau(t)$, will sell stocks, if the relative loss (negative profitability $-p(t, i)$ is greater as compared with the transaction cost $-p(t, i)>\tau(t)$, and will do nothing, if $-\tau(t) \leqslant p(t, i) \leqslant \tau(t)$. Here the relative transaction cost is defined as the relation

$$
\tau(t)=\frac{\tau_{0}}{n(t) Z(t)},
$$

\footnotetext{
${ }^{5}$ The term 'actual' means simulated by USEGM.

${ }^{6}$ In finance, a haircut is a part that is subtracted from the value of the assets that are being used as collateral. The size of the haircut reflects the perceived risk associated with holding the assets.

${ }^{7}$ The term "profit" can define losses if negative terms prevail.
} 
where $\tau_{0}$ is the actual transaction cost and $n(t)$ is the number of transaction stocks. From equality $\tau(t)=p(t, i)$ it follows that a minimal number of stocks to cover transaction expenses is

$$
n(t)=\frac{\tau_{0}}{p(t, i) Z(t)}
$$

Therefore, the buying-selling strategy $S(t, i)$ of the customer $i$ at time $t$ in terms of profitability levels:

$$
S(t, i)= \begin{cases}\text { buy } n_{b}(t, i) \geqslant n(t) \text { stocks, } & \text { if } p(t, i) \geqslant \tau(t), \\ \text { sell } n_{s}(t, i) \geqslant n(t) \text { stocks, } & \text { if } p(t, i) \leqslant-\tau(t), \\ \text { wait, } & \text { otherwise. }\end{cases}
$$

From expressions (1) and (2), the buying-selling strategy $S(t, i)$ in terms of stock price levels

$$
S(t, i)= \begin{cases}\text { buy } n_{b}(t, i) \geqslant n(t) \text { stocks, } & \text { if } Z(t) \leqslant z_{b}(t, i), \\ \text { sell } n_{s}(t, i) \geqslant n(t) \text { stocks, } & \text { if } Z(t) \geqslant z_{s}(t, i), \\ \text { wait, } & \text { otherwise. }\end{cases}
$$

Here the buying price level of the player $i$ at time $t$ is

$$
z_{b}(t, i)=z(t+1, i) /(1-\delta(t)+\alpha(t)+h(t)+\tau(t)) .
$$

The selling price level of the player $i$ at time $t$ is

$$
z_{s}(t, i)=z(t+1, i) /(1-\delta(t)+\alpha(t)+h(t)-\tau(t)),
$$

where $z(t+1, i)$ is the stock price predicted by the investor $i$ at time $t+1$.

The market buying price at time $t$ is the largest buying price of players $i=1, \ldots, I$

$$
z_{b}(t)=z_{b}\left(t, i^{\max }\right), \quad \text { where } i^{\max }=\arg \max _{i} z_{b}(t, i)
$$

The market selling price at time $t$ is the lowest selling price of players $i=1, \ldots, I$

$$
z_{s}(t)=z_{b}\left(t, i^{\min }\right), \quad i^{\min }=\arg \min _{i} z_{s}(t, i)
$$

The actual price of a stock at time $t+1$ is defined as the price of a previous deal of major stockholders plus the noise representing the remaining small stockholders. The noise $\epsilon(t)$ is defined by truncated Gaussian distribution with variance reflecting stock volatility. The Gaussian distribution follows from the assumption that the noise is a sum of independent random numbers representing the buying-selling actions of large number of small stockholders.

$$
Z(t+1)= \begin{cases}z_{b}(t)+\epsilon(t+1), & \text { if } Z(t)<z_{b}(t) \\ z_{s}(t)+\epsilon(t+1), & \text { if } Z(t)>z_{s}(t) \\ Z(t)+\epsilon(t+1), & \text { otherwise }\end{cases}
$$


The market buying price at time $t$ is the largest buying price of players $i=1, \ldots, I$

$$
z_{b}(t)=z_{b}\left(t, i^{\max }\right), \quad \text { where } i^{\max }=\arg \max _{i} z_{b}(t, i)
$$

The market selling price at time $t$ is the lowest selling price of players $i=1, \ldots, I$

$$
z_{s}(t)=z_{s}\left(t, i^{\min }\right), \quad i^{\min }=\arg \min _{i} z_{s}(t, i)
$$

The number of stocks owned by the player $i$ at time $t+1$ is

$$
N(t+1, i)= \begin{cases}N(t, i)+n_{b}(t, i), & \text { if } Z(t)<z_{b}(t) \\ N(t, i)-n_{s}(t, i), & \text { if } Z(t)>z_{s}(t) \\ N(t, i), & \text { otherwise }\end{cases}
$$

Here $n_{b}(t, i)$ and $n_{s}(t, i)$ are the numbers of stocks for buying and selling operations by the player $i$ at time $t$.

\subsection{Investors' Profit}

The product $N(0, i) Z(0, i)$ is the initial investment to buy $N(0, i)$ shares by the investors' own capital at initial price $Z(0, i)$. The initial funds to invest are $C_{0}(0, i)$ and the initial credit limit is $L(0, i)$.

$L(t, i), t=1, \ldots, T$ is the credit available for a customer $i$ at time $t$. The investors' own funds $C_{0}(t, i)$ to invest at time $t$ are

$$
C_{0}(t, i)=C_{0}(t-1, i)-(N(t, i)-N(t-1, i)) Z(t)
$$

Here the product $(N(t, i)-N(t-1, i)) Z(t)$ defines the money involved in buying-selling stocks.

Stocks are obtained using both investors own money $C_{0}(t, i)$ and the funds $b(t, i)$ borrowed at moment $t$. The borrowed sum of the stockholder $i$ accumulated at time $t$ is

$$
B(t, i)=\sum_{s=1}^{t} b(s, i)
$$

The symbol $b(t, i)$ shows what the user $i$ borrows at moment $t$

$$
b(t, i)=\left\{\begin{array}{l}
-C_{0}(t, i), \quad \text { if }-L(t, i) \leqslant C_{0}(t, i)<0, \\
0, \quad \text { if } 0 \leqslant C_{0}(t, i), \\
\text { insolvent at moment } t=t_{i}^{*}, \\
\quad \text { if }-L(t, i)>C_{0}(t, i)-B_{\text {sum }}(t, i)+N(t, i) Z(t) .
\end{array}\right.
$$


Expression (13) is for long-term loans where frequent transactions are not economical or restricted by contracts. The advantage is lower interest rate $\gamma(t)$.

$$
b(t, i)=\left\{\begin{array}{l}
-C_{0}(t, i), \quad \text { if }-L(t, i) \leqslant C_{0}(t, i)<0 \\
-C_{0}(t, i), \quad \text { if } 0 \leqslant C_{0}(t, i)<B(t, i) \\
0, \quad \text { if } B(t, i) \leqslant C_{0}(t, i), \\
\text { insolvent at moment } t=t_{i}^{*}, \\
\quad \text { if }-L(t, i)>C_{0}(t, i)-B_{\text {sum }}(t, i)+N(t, i) Z(t) .
\end{array}\right.
$$

According to the second line in expression (14), the user $i$ "borrows" a negative sum $b(t, i)=-C_{0}(t, i)$ if $0<C_{0}(t, i) \leqslant B(t, i)$, which means that the user pays back a part $b(t, i)$ of the loan $B(t, i)$ using available funds $C_{0}(t, i)$. This expression is for short-term loans with possibility of frequent transactions. The disadvantage is a higher interest rate $\gamma(t)$.

The general borrowing expenses are

$$
B_{\mathrm{sum}}(t, i)=B(t, i)+\sum_{s=1}^{t} B(s, i) \gamma(s, i),
$$

where the first term denotes the loan accumulated at time $T$ and the second term shows the interest.

An investor (stockholder) gets a profit as the difference between the income from selling and buying stocks $D(t, i)$ and expenses for borrowing funds $B_{\text {sum }}(t, i)$

$$
U(t, i)=D(t, i)-B_{\mathrm{sum}}(t, i)
$$

where

$$
D(t, i)=N(t, i) Z(t)-N(0, i) Z(0)
$$

The funds available for the investor $i$ at time $t$ are

$$
C(t, i)=C_{0}(t, i)+L(t, i)-B_{\mathrm{sum}}(t, i)
$$

An investor is trying to maximize gains by borrowing money to invest in shares that appreciate more than what it costs him by way of interest. It means leveraging shares for an investment.

The number of stocks $n_{b}(t)$ to buy at the time $t$ is restricted by inequality:

$$
n(t) \leqslant n_{b}(t, i) \leqslant C(t, i) / Z(t)
$$

Here the first part of the inequality restricts transaction costs. According to expression (13), the stockholder will be insolvent at the time $t=t_{i}^{*}$ if the loan exceeds the assets

$$
B_{\mathrm{sum}}\left(t_{i}, i\right)>C_{0}\left(t_{i}, i\right)+L\left(t_{i}, i\right)+N(t, i) Z(t)
$$


since there will not be enough money to pay back all the borrowing expenses $B_{\text {sum }}\left(t_{i}^{*}, i\right)$. This can happen without buying additional stocks, because the interest $B_{\text {sum }}(t, i)$ accumulates automatically.

Considering multi-level operations, we shall define additional restrictions (33) on the number of stocks $n_{b}(t)$.

\subsection{Bank Profit}

It follows from (20) that the bank losses at time $t_{i}^{*}$ are

$$
B_{\text {loss }}\left(t_{i}^{*}, i\right)=B_{\text {sum }}\left(t_{i}^{*}, i\right)-C_{0}\left(t_{i}^{*}, i\right)-N\left(t_{t}^{*}, i\right) Z\left(t_{i}^{*}\right) .
$$

The total bank losses accumulated at time $t \geqslant \max _{i} t_{i}^{*}$ are

$$
B_{\mathrm{loss}}(t)=\sum_{i} B_{\mathrm{loss}}\left(t_{i}^{*}, i\right)
$$

The bank income

$$
D(t)=\sum_{s=1}^{t} \sum_{i-1}^{I} B(s, i) \gamma(s, i) .
$$

The bank profit

$$
U(t)=D(t)-B_{\text {loss }}(t) .
$$

\subsection{Multi-Level Operations}

In the opinion of some professional brokers we have interviewed, one needs at least three buying profitability levels $p_{b}(t, i, l), l=1,2,3$, where

$$
p_{b}(t, i, l+1)>p_{b}(t, i, l), \quad p_{b}(t, i, 1)=\tau(t),
$$

and three selling profitability levels $p_{s}(t, i, l), l=1,2,3$, where

$$
\begin{aligned}
& p_{s}(t, i, l+1)<p_{s}(t, i, l), \quad p_{s}(t, i, 1)=-\tau(t), \\
& p_{b}(t, i, l)>p_{s}(t, i, 1) .
\end{aligned}
$$

to explain the behavior of major stockholders. The level $l=1$ means to buy-sell the minimal number of stocks. The level $l=3$ means to buy-sell as much stocks as possible, and the level $l=2$ is in the middle. Thus, the number of stocks to buy-sell at time $t$ and the buying profitability level $l=1$ are

$$
n_{b}(t, i, 1)=n_{s}(t, i, 1)=n(t) \text {, }
$$


where $n(t)$ is from expression (6). The number of stocks to buy at time $t$ and buying profitability level $l=3$

$$
n_{b}(t, i, 3)=\operatorname{int}(C(t, i) / Z(t))
$$

where $C(t, i)$ is the investor's $i$ funds available at time $t$ defined by expression (18). Hence, the number of stocks to buy at time $t$ and the buying profitability level $l=2$ are

$$
n_{b}(t, i, 2)(t)=\operatorname{int}((C(t, i) / Z(t)+n(t)) / 2) .
$$

The number of stocks to be sold at time $t$ and the selling profitability level $l=3$ are

$$
n_{s}(t, i, 3)=N(t, i)
$$

The number of stocks to be sold at time $t$ and the selling profitability level $l=2$ are

$$
n_{s}(t, i, 2)=\operatorname{int}((N(t, i)+n(t)) / 2) \text {. }
$$

where $N(t, i)$ is the number of stocks available at time $t$.

The general buying-selling strategy $S_{0}(i)$ of the investor $i$ at time $t+1$ is

$$
S_{0}(i)= \begin{cases}\text { wait }, & \text { if }-\tau(t) \leqslant p(t, i) \leqslant \tau(t), \\ \text { use active strategy } S(l, i), & \text { otherwise }\end{cases}
$$

where the active strategy $S(l, i)$ is as follows

$$
S(1, i)= \begin{cases}\text { buy } n_{b}(t, i, 3) \text { stocks, } & \text { if } p(t, i) \geqslant p_{b}(t, i, 3), \\ \text { buy } n_{b}(t, i, 2) \text { stocks, }, & \text { if } p(t, i) \geqslant p_{b}(t, i, 2), \\ & \text { and } p(t, i)<p_{b}(t, i, 3), \\ \text { buy } n_{b}(t, i, 1) \text { stocks, }, & \text { if } p(t, i) \geqslant p_{b}(t, i, 1)=\tau(t), \\ & \text { and } p(t, i)<p_{b}(t, i, 2), \\ \text { sell } n_{s}(t, i, 1), \text { stocks } & \text { if } p(t, i) \leqslant p_{s}(t, i, 1)=-\tau(t), \\ & \text { and } p(t, i)>p_{s}(t, i, 2), \\ \text { sell } n_{s}(t, i, 2) \text { stocks, }, & \text { if } p(t, i) \leqslant p_{s}(t, i, 2), \\ & \text { and } p(t, i)>p_{s}(t, i, 3), \\ \text { sell } n_{s}(t, i, 3) \text { stocks, }, & \text { if } p(t, i) \leqslant p_{s}(t, i, 3), \\ \text { wait, } & \text { otherwise. }\end{cases}
$$

Here $p(t, i)$ is profitability of investor $i$ at time $t$ defined by (2) and the profitability levels are defined by the equalities

$$
\begin{aligned}
& p_{b}(t, i, l)=\tau(t) l, \\
& p_{s}(t, i, l)=-\tau(t) l, \quad l=1,2,3 .
\end{aligned}
$$


Using this strategy, the number of stocks owned by the player $i$ at time $t+1$ is

$$
N(t+1, i)= \begin{cases}N(t, i)+n_{b}(t, i, 3), & \text { if } p(t, i) \geqslant p_{b}(t, i, 3), \\ N(t)+n_{b}(t, i, 2), & \text { if } p(t, i) \geqslant p_{b}(t, i, 2), \\ N(t)+n_{b}(t, i, 1) \text { stocks, } & \text { and } p(t, i)<p_{b}(t, i, 3), \\ N(t)-n_{s}(t, i, 1), \text { stocks } & \text { and } p(t, i)<p_{b}(t, i, i, 2), \\ & \text { if } p(t, i) \leqslant p_{s}(t, i, 1)=-\tau(t), \\ N(t)-n_{s}(t, i, 2) \text { stocks, } & \text { if } p(t, i) \leqslant p_{s}(t, i, 2), \\ & \text { and } p(t, i)>p_{s}(t, i, 3), \\ N(t)-n_{s}(t, i, 3) \text { stocks, }, & \text { if } p(t, i) \leqslant p_{s}(t, i, 3), \\ N(t), & \text { otherwise. }\end{cases}
$$

The buying-selling prices of the player $i$ at time $t$ depends on the buying-selling levels $l$. Extending single-level conditions (7) and (8) to the multi-level case of active strategy $S(l, i)$, the buying-selling price levels are as follows

$$
\begin{aligned}
& z_{b}(t, i, l)=z(t+1, i) /\left(1-\delta(t)+\alpha(t)+h(t)+p_{b}(t, i, l)\right), \\
& z_{s}(t, i, l)=z(t+1, i) /\left(1-\delta(t)+\alpha(t)+h(t)+p_{s}(t, i, l)\right), \quad l=1,2,3 .
\end{aligned}
$$

It follows from (25) and (26) that

$$
\begin{aligned}
& z_{b}(t, i, l+1)<z_{b}(t, i, l) \\
& z_{s}(t, i, l+1)>z_{s}(t, i, l) \\
& z_{s}(t, i, l)>z_{b}(t, i, l), \quad l=1,2,3 .
\end{aligned}
$$

The actual price of a stock at time $t+1$ is defined as the price of a previous deal of major stockholders plus the Gaussian noise representing the remaining small stockholders.

\subsection{Prediction Parameters}

\subsection{1. $A R(p)$ Model}

The profit (16) of the player $i$ depends on the accuracy of prediction $\beta(s, i)$ made at time $s, s=1, \ldots, t$, where $t$ denotes the present time. Define the $\operatorname{AR}(p)$ model of order $p$ as

$$
z(s)=\sum_{k=1}^{p} a_{k} z(s-k)+\epsilon_{s} .
$$

In this and the next section, the symbol $z(t)$ denotes the simulated stock rate at time $t$, or the historical stock prices, if these are used for the evaluation of the expected profit by USEGM. The USEGM model starts at time $s=1$, so we should define the past values 
$z(1-p)$. We assume that

$$
z(s)=z(1)(1-s) \eta, \quad \epsilon_{s}=0, \quad \text { if } s<1 .
$$

where $z(1)$ is the initial price and $0<\eta<1$ is a fixed number. If $s=t+1$, then $\epsilon_{s}$ is a Gaussian random variable with zero expectation and positive variance (stock volatility). If $1 \leqslant s \leqslant t$, then $\epsilon_{s}$ are residuals of the prediction model. Using equalities (38) and (39), we define residuals by the expressions

$$
\begin{aligned}
& \epsilon_{1}=z(1)-a_{1} z(0)-\cdots-a_{2} z(1-p), \\
& \epsilon_{2}=z(2)-a_{1} z(1)-\cdots-a_{2} z(2-p) \text {, }
\end{aligned}
$$

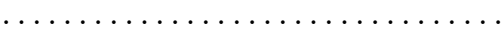

$$
\begin{aligned}
& \epsilon_{t}=z(t)-a_{1} z(t-1)-\cdots-a_{p} z(t-p)
\end{aligned}
$$

Assume that the player $i$ predicts using the $\operatorname{AR}(p) \operatorname{model}^{8}$ of order $p$ with the "memory" parameter $p$. Then the residual $\epsilon_{s}(i)$ of the player $i$ prediction at the time $s \leqslant t$ is defined by the equality below

$$
z(s, i)=\sum_{k=1}^{p} a_{k}^{i} z(s-k, i)+\epsilon_{s}(i)
$$

The scale parameters $a_{k}^{i}$ are defined by the condition

$$
a_{k}^{i}=\arg \min _{a_{k}^{i}} \sum_{s=1}^{t} \epsilon_{s}^{2}(i)
$$

where

$$
\epsilon_{s}(i)=z(s, i)-\sum_{k=1}^{p} a_{k}^{i} z(s-k, i)
$$

Condition (42) can be reduced to solution of the system of linear equations:

$$
x=A^{-1} B,
$$

where $A=A(k, j), k, j=1, \ldots, p, B=B(k), k=1, \ldots, p, x=\left(x_{k}, k=1, \ldots, p\right)$ and $x_{k}$ defines the optimal value of $a_{k}=x_{k}$.

Here

$$
A(k, j)=\sum_{s=1}^{t} z(s-k) z(s-j), B(k)=\sum_{s=1}^{t} z(s) z(s-k) .
$$

${ }^{8}$ Professional investors are trying to obtain additional information about the fundamentals of the stock directly or by sophisticated statistical models. Thus the $\operatorname{AR}(p)$ model can be regarded as a simple initial approximation of a nonprofessional player. 


\subsection{2. $A R-A B S(p)$ Model}

To reflect risk-neutral market participants, we minimize the sum of absolute values of the residuals in the regressive model (38) of order $p$. It explains the acronym $\operatorname{AR}-\operatorname{ABS}(p)$.

The method of least squares is sensitive to large deviations (Arthanari and Dodge, 1993). Therefore, the replacement of squares by absolute values is beneficial, if the customers' utility function is linear. The linear utility function represents risk-neutral behavior.

Minimization of Residuals in $A R-A B S(p)$ Models. To minimize $f(x)$, we apply linear programming.

$$
\begin{aligned}
& \min _{v, u} \sum_{s=1}^{t} u_{s}, \\
& u_{s} \geqslant \epsilon_{s}, \quad s=1, \ldots, t, \\
& u_{s} \geqslant-\epsilon_{s}, \quad s=1, \ldots, t, \\
& u_{s} \geqslant 0, \quad s=1, \ldots, t .
\end{aligned}
$$

Here

$$
\begin{aligned}
& u=\left(u_{s}^{1}, u_{t}^{2}, s=1, \ldots, t\right), \\
& v=\left(v_{k}^{1}, v_{k}^{2}, k=1, \ldots, p\right), \\
& u_{s}=u_{s}^{1}-u_{s}^{2}, \quad s=1, \ldots, t, \\
& u_{s}^{j} \geqslant 0, \quad v_{k}^{j} \geqslant 0, \quad j=1,2,
\end{aligned}
$$

where $v, u$ are auxiliary variables and $\epsilon_{s}$ are residuals defined by differences of the auxiliary variables $v$ :

$$
\epsilon_{s}=z(s)-\sum_{k=1}^{p}\left(v_{k}^{1}-v_{k}^{2}\right) z(s-k) .
$$

If $\epsilon_{s}=\epsilon_{s}(i)$, where $\epsilon_{s}(i)$ are residuals of the player $i$, then the scale parameters $a_{k}^{i}$ of the player $i$ are obtained by solving the LP problem (46) as differences of the corresponding auxiliary variables $a_{k}^{i}=v_{k}^{1}-v_{k}^{2}$.

\subsection{Dynamic Margins and Haircuts}

The buying and selling levels depend on the results of investment operation. To avoid risky investments, the margins between buying and selling levels $m(t, i)=p_{b}^{\prime}(t, i)-$ $p_{s}^{\prime}(t, i) \geqslant 2 \tau(t)$ are increased after an unsuccessful investment. Here $p_{b}^{\prime}(t, i) p_{s}^{\prime}(t, i)$ denote dynamic profitability levels. To increase the expected profit, the margin $m(t, i)$ is decreased after a success. For simplicity, linear strategies are applied. It means that 
$m(t, i)=p_{b}^{\prime}(t, i)-p^{\prime} s(t, i)$. Here

$$
\begin{aligned}
& p_{b}^{\prime}(t+1, i)= \begin{cases}p_{b}^{\prime}(t, i)\left(1+k_{m}(i)(U(t, i)-U(t-1, i)),\right. & \\
\text { if } p_{b}^{\prime}(t, i)\left(1+k_{m}(i)\right) \geqslant \tau(t), & \text { otherwise, } \\
p_{b}(t, i), & \end{cases} \\
& p_{s}^{\prime}(t+1, i)=\left\{\begin{array}{cc}
p_{s}^{\prime}(t, i)\left(1+k_{m}(i)(U(t, i)-U(t-1, i)),\right. & \\
\text { if } p_{s}^{\prime}(t, i)\left(1+k_{m}(i)\right) \leqslant-\tau(t), & \text { otherwise. } \\
p_{s}^{\prime}(t, i), &
\end{array}\right.
\end{aligned}
$$

Here the parameter $-1<k_{m}(i) \leqslant 1$ shows how the dynamic margins $p_{b}^{\prime}(t)$ and $p_{s}^{\prime}(t)$, where $p_{b}^{\prime}(1)=p_{b}(1), p_{s}^{\prime}(1)=p_{s}(1)$ depend on the profitability $p(t, i)$. We assume that, in the dynamic mode, the buying-selling stock numbers $n_{b}(t, i, l), n_{s}(t, i, l), l=1,2,3$ remain the same as in the static mode. In addition, the manually controlled profitability levels $p_{b}(t, i, 4), p_{s}(t, i, 4)$ using $n_{b}(t, i, 3), n_{s}(t, i, 3)$ are included for market manipulation.

To control the risk, banks define haircuts as a function of bank profit $U(t)$ for lending funds to investors. The bank profit is the difference between the gains for lending money and losses due to borrowers' defaults. Assuming a linear haircut strategy

$$
h(t+1)= \begin{cases}h(t)\left(1+k_{h}(U(t)-U(t-1))\right), & \text { if } h(t)\left(1-k_{h} U(t)\right) \geqslant h_{\min }, \\ h_{\min }, & \text { otherwise, }\end{cases}
$$

where $-1<k_{h} \leqslant 1$ and $h_{\min }$ is the minimal haircut defined by transaction expenses.

\subsection{Search for Nash Equilibrium}

\subsubsection{Equilibrium in Memory Parameters}

Memory parameters $p^{9}$ reflect a personal opinion of an individual investor $i$ and, in search of the Nash equilibrium, will be regarded as some variable $p=p_{i}, p_{i}=1,2, \ldots, m$, $i=1, \ldots, I$. Here $p_{i}=0$ refers to the Wiener model with the parameters $p=1, a_{1}=1$, and $p_{i}=m>0$ means the $\operatorname{AR}(p)$ or $\operatorname{AR}-\operatorname{ABS}(p)$ model with the parameter $p=m$.

Denote by $p^{0}=\left(p_{i}^{0}, i=1, \ldots, I\right)$ a 'keep-contract' vector and by $p^{\max }=$ $\left(p_{i}^{\max }, i=1, \ldots, I\right)$ a 'max-profit' vector, where

$$
p_{i}^{\max }=\arg \max _{p_{i}} U\left(T, i, p_{i}, \bar{p}_{i}{ }^{0}\right), \quad i=1, \ldots, I .
$$

Here $\bar{p}_{i}{ }^{0}=\left(p_{k}^{0}, k=1, \ldots, I, k \neq i\right)$, and $U\left(T, i, p_{i}, \bar{p}_{i}{ }^{0}\right)$ is the accumulated profit of the player $i$, predicted using the $\operatorname{AR}(p)$ or $\operatorname{AR}-\operatorname{ABS}(p)$ model with $p=p_{i}$ while other players $k \neq i$ predict by the same model with the equilibrium parameters $p=p_{k}^{0}, k \neq i$.

\footnotetext{
${ }^{9}$ The symbol $p$ is used for the memory parameter $p$, for profitability $p(t, i)$, and for buying-selling levels $p_{b}(t, i), p_{s}(t, i)$, the specific meaning is defined by different indexes.
} 
Denote by $U\left(T, i, p_{i}^{\max }\right)$ the profit of the player $i$ using the 'max-profit' parameters. Denote

$$
p^{*}=\arg \min _{p^{0}} \sum_{i=1 \ldots, I}\left(U\left(T, i, p_{i}^{\max }\right)-U\left(T, i, p_{i}^{0}\right)\right)
$$

where $p^{0}=\left(p_{i}^{0}, i=1, \ldots, I\right)$. Expression (55) denotes the minimum of the sum of players' profits obtained by violating the NE strategy, while other players follow the NE strategies. Parameters $p^{*}=\left(p_{i}^{*}, i-1, \ldots, I\right)$ define NE exactly, if sum (55) is zero and approximately, if the sum is less then the simulation error.

Strategies $p_{i}$ are discrete, so NE may not exist. In such a case, to satisfy the sufficient conditions of the Nash equilibrium (Nash, 1951), we introduce mixed strategies $x=$ $\left(x_{i}, i=1, \ldots, I\right), x_{i}=P\left\{p=p_{i}\right\}$, where $P$ is a probability of the event $p=p_{i}$. Then we search for such a contract vector $x^{0}=\left(x_{i}^{0}, i=1, \ldots, I\right), \sum_{i=1, \ldots, I} x_{i}=1, x_{i} \geqslant 0$ that minimizes the sum of differences between 'max-profit' and 'keep-contract' profits

$$
x^{*}=\arg \min _{x^{0}} \sum_{i=1}^{I}\left(U\left(T, i, x_{i}^{\max }\right)-U\left(T, i, x_{i}^{0}\right)\right), \quad i=1, \ldots, I .
$$

Here, the symbol $U\left(T, i, x^{0}\right)$, defines the profit of the player $i$. when all the players keep the contract parameters $x_{i}^{0}$. The symbol $U\left(T, i, x_{i}^{\max }\right)$ denotes the maximal profit of the player $i$, when other players keep the contract parameters $x_{k}^{0}, k \neq i$. Therefore, the vector $x^{*}$ defines the Nash equilibrium exactly if the sum (56) is zero. The vector $x^{*}$ defines the Nash equilibrium approximately, if the sum is less than the simulation error. However, applying the mixed strategies $x$, one introduces additional simulation errors which may exceed the discrete approximation errors while using pure strategies $p$.

Expressions (55) and (56) define stochastic global optimization problems. The Bayesian Approach (Mockus et al., 1997) is meant for these problems. Other well-known global optimization methods (Strongin and Sergeyev, 2000; Dzemyda and Sakalauskas, 2011) can be applied, too.

\subsubsection{Equilibrium in Margins and Haircuts}

Condition (56) defines the Nash equilibrium on a set of different prediction models $\operatorname{AR}(p)$ or AR-ABS, assuming that investors keep constant buying-selling margins $m(t, i)=$ $m(i)$ for customers $i$. To reflect the influence of margins, Nash equilibrium condition (56) is extended by including the margin strategies $y_{i}=k_{m}(i)$. Then, it follows from (56) and (52) that

$$
\delta^{\max }=\min _{p_{i}^{0}, y_{i}^{0}} \sum_{i=1}^{I}\left(U\left(T, i, p_{i}^{\max }, y_{i}^{\max }\right)-U\left(T, i, p_{i}^{0}, y_{i}^{0}\right)\right), \quad i=1, \ldots, I .
$$


This model includes the parameters of investors. To include the parameters of the lending bank, the haircut strategy $v_{i}=k_{h}(i)$ is added to condition (57)

$$
\begin{aligned}
& \delta^{\max }=\min _{p_{i}^{0}, y_{i}^{0}, v^{0}} \sum_{i=1}^{I}\left(U\left(T, i, p_{i}^{\max }, y_{i}^{\max }, v^{\max }\right)-U\left(T, i, p_{i}^{0}, y_{i}^{0}, v^{0}\right)\right), \\
& i=1, \ldots, I .
\end{aligned}
$$

In expressions (57) and (58) the parameters $y_{i}^{0}, y_{i}^{\max }, v^{0}, v^{\max }$ are defined in a way similar to that of the parameters $p_{i}^{0}, p_{i}^{\max }$ in (55).

\section{Examples of the Stock Exchange Game Model}

In Fig. 1, the lower line represents the profit of a single player that uses the $\operatorname{AR}(p), p=9$ model. The upper line shows the profit of the remaining seven players that use the Wiener model. The time period is three years (virtual).

Figure 2 illustrates the "mixed" case: the upper line represents the profit of a single player that uses the Wiener model. The remaining lines show profits of the remaining seven player that use different prediction models, from $\operatorname{AR}(1)$ to $\operatorname{AR}(7)$.

Figures 3 shows the corresponding stock rates..

These figures illustrate that, in the examples the Wiener model approximately provides the Nash equilibrium. Figures 4 and 5 illustrate a virtual "crisis" when stock prices are nearly zero and no one wants to buy them.

Another way of testing the USEGM model is to investigate the reaction to well known deliberately non-NE strategies of some major stockholder. An example is George Soros' currency manipulation by selling a large amount of assets to buy back these and other assets later at an artificially lowered price. An important feature of this scenario is that the

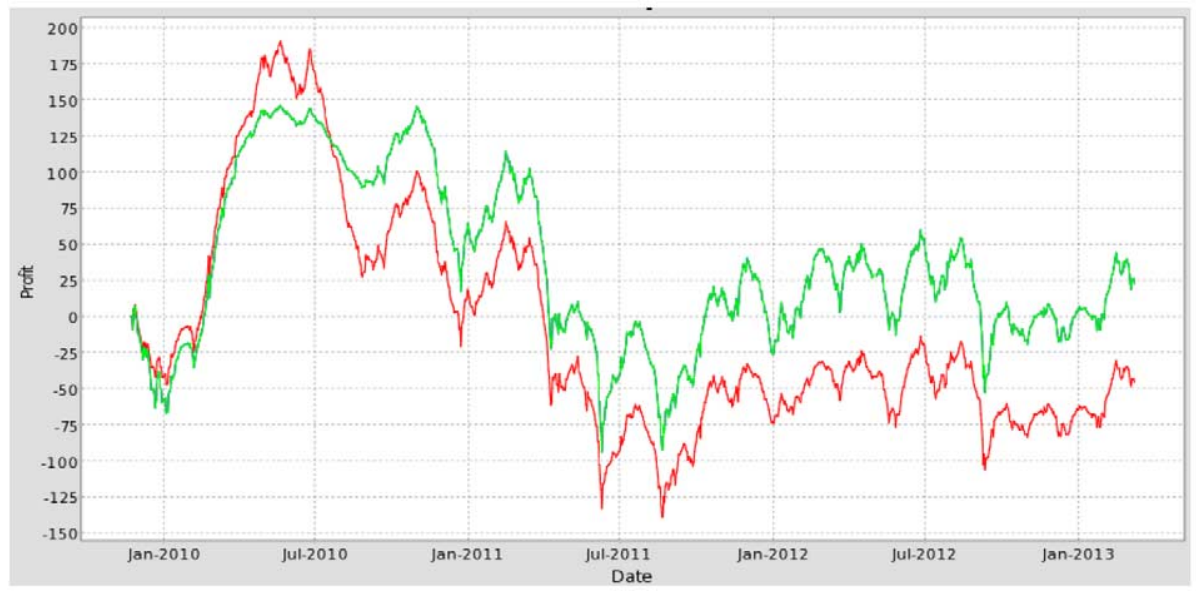

Fig. 1. Profit of $\operatorname{AR}(p), p=9$ vs the Wiener model. 


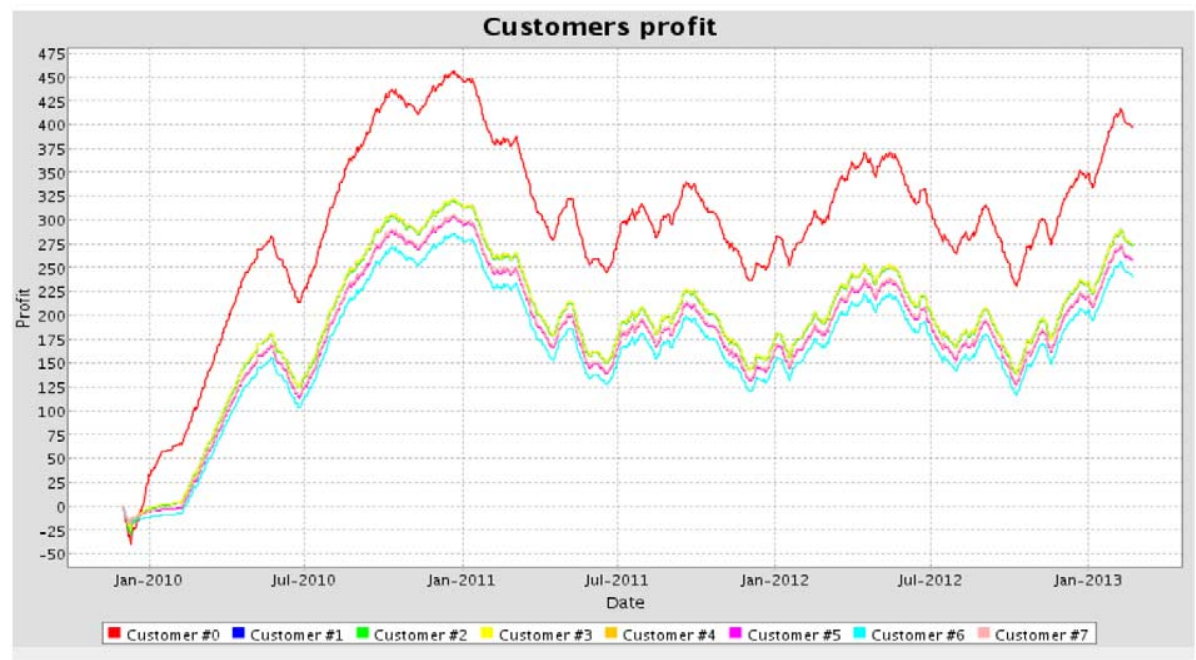

Fig. 2. Profit in the Wiener model versus $\operatorname{AR}(p)$ models, $p=1-7$.

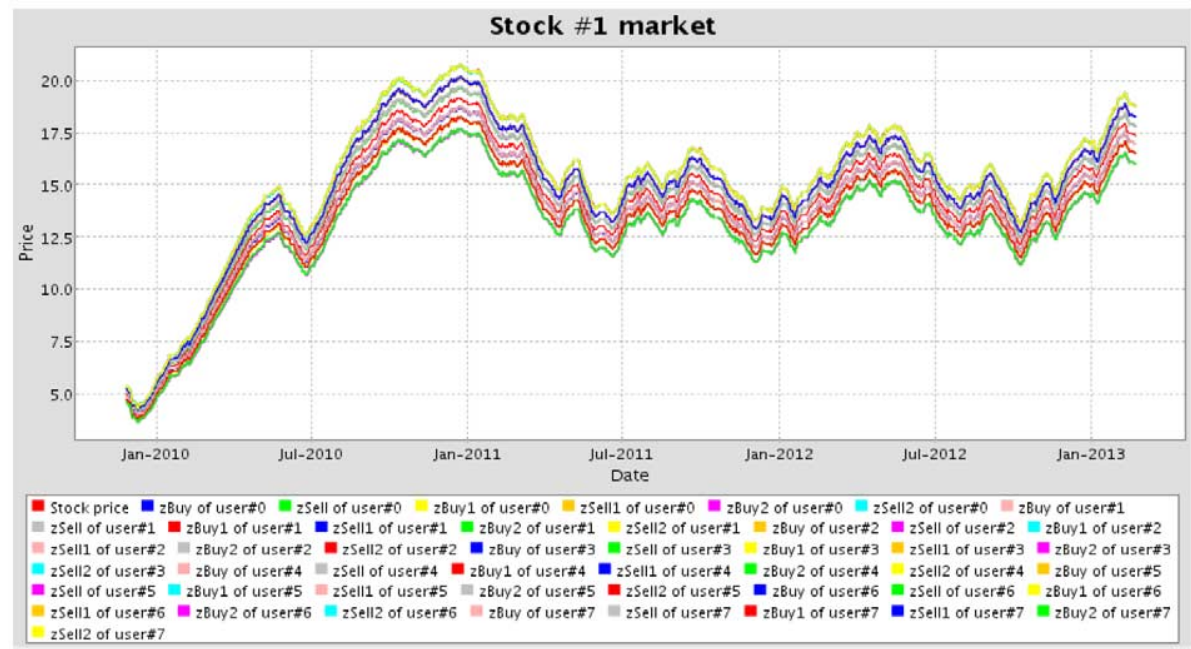

Fig. 3. Stock price in the Wiener model versus $\operatorname{AR}(p)$ models, $p=1-7$.

player "Soros" makes great profit if other players are predicting prices by the previous data, for example, by $\operatorname{AR}(p), p>1$. In Fig. 6, the lower line represents the profits of seven players that use the $\operatorname{AR}(p), p=9$ model. The upper line shows the profit of a player that uses the "Soros" model.

In Fig. 7, the middle line represents the stock price in the "Soros-vs-AR $(p, p=9)$ " game. The other six lines show buying and selling levels.

Figure 8 shows the historical stock rates of Google and Intel. Different scales of stock prices are used here, the scale of Intel stocks is 25 USD. 


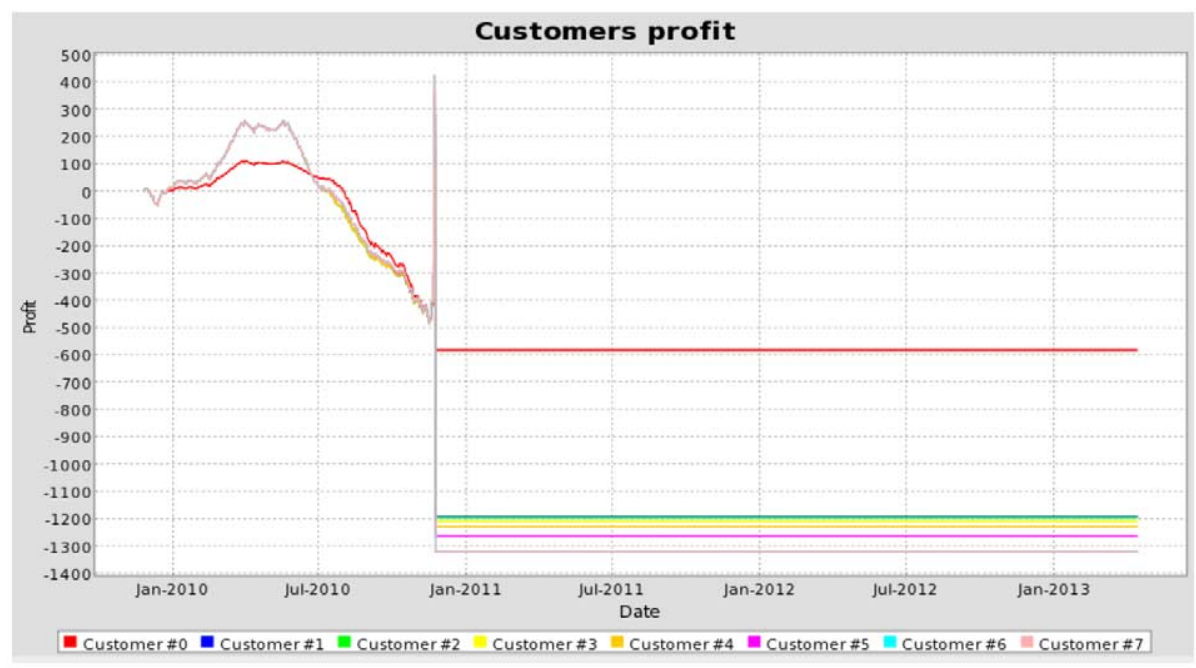

Fig. 4. Profits when the crisis occurs.

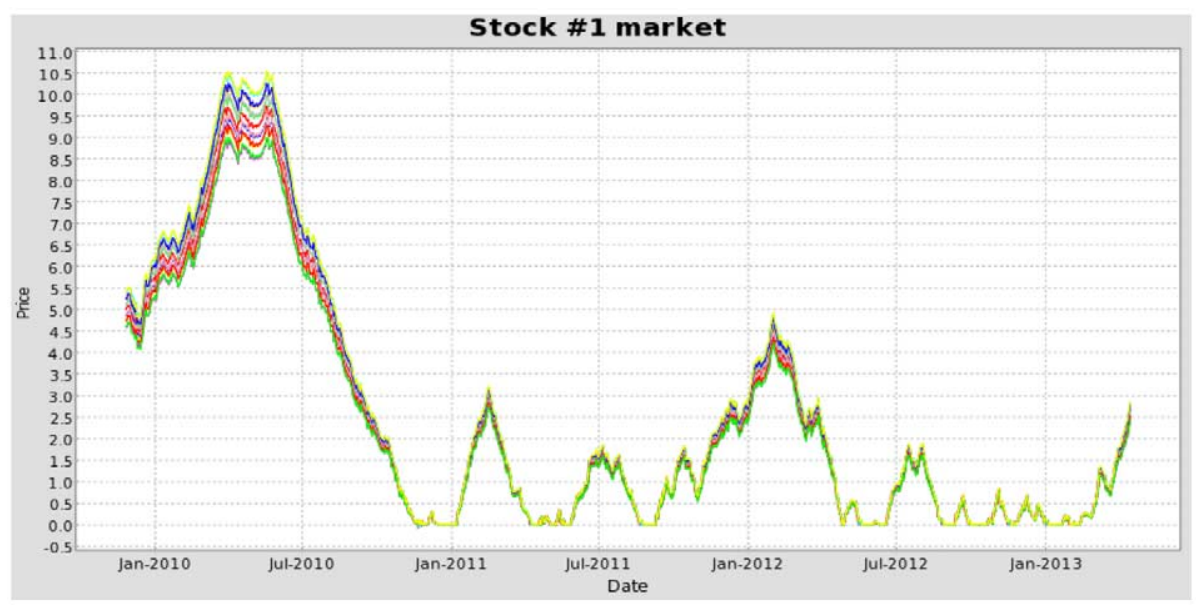

Fig. 5. Stock prices when the crisis occurs.

Comparing these actual stock rates with the corresponding simulated data in Fig. 3, one can notice obvious differences and some similarities.

\section{Examples of Financial Time Series}

To compare the simulation results with real data, an efficient market hypothesis has also been tested, using financial time series of eighteen assets. In this experiment, the simple SEGM model was applied. Five simulated financial time series, the Amazon river discharge, and the demand of a call center were regarded, too, to illustrate the differences. Time series are selected so as to represent various asset sectors. 


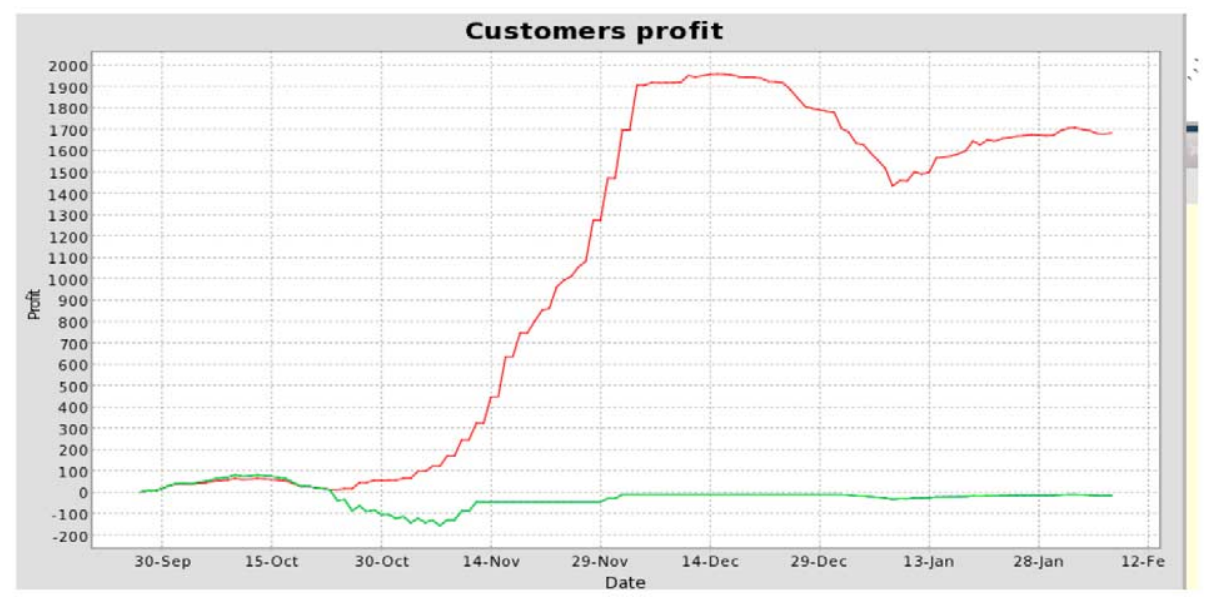

Fig. 6. Profits in the "Soros-vs-AR( $(p, p=9)$ " game.

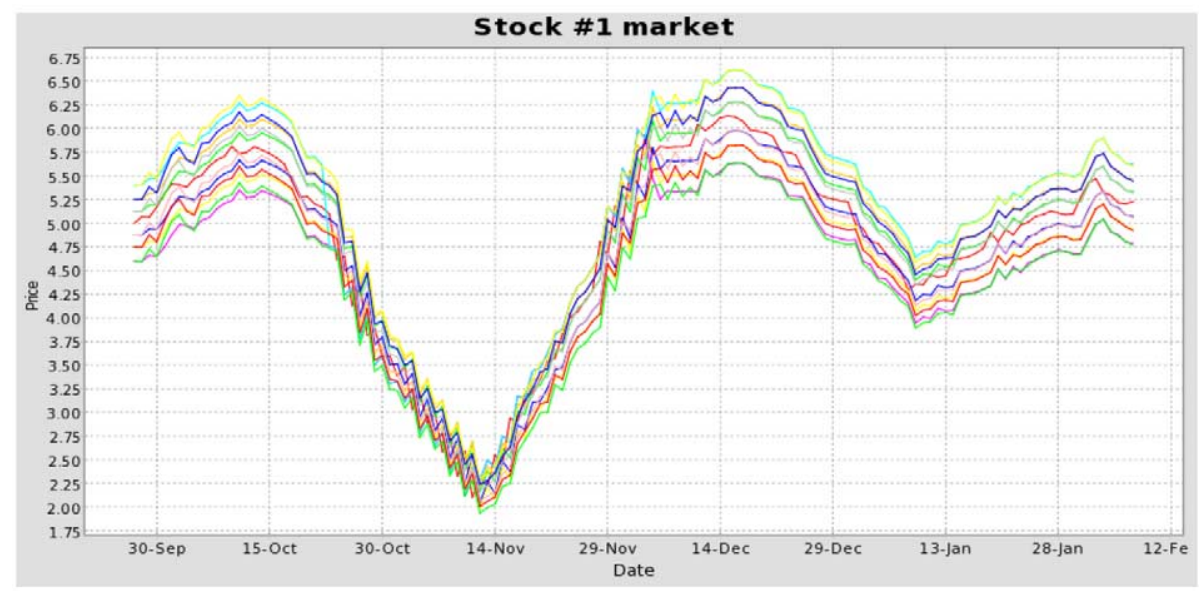

Fig. 7. Stock price in the "Soros-vs-AR $(p), p=9$ " game.

In Table 1 nine assets are used in evaluations. The prices are predicted. Eight assets are real-world futures closing prices. The ninth 'asset' is a random simulation. Random independent Gaussian numbers are summed up cumulatively to simulate 'closing prices' for random data representing the Wiener model.

500 data points are used for training and the remaining 250 points are used for evaluation. The training data points represent approximately 2 years of history prior to January 1,2007 . This is the pre-crisis time. The training data are divided into two equal parts. In the first part, the scale parameters $a_{i}, i=1, \ldots, p$ of the $\operatorname{AR}-\operatorname{ABS}(p)$ model of order $p$ are evaluated for each parameter $p$. The second part of training data is used to optimize $p$. The evaluation data points represent approximately one year of history after January 1, 2007. 


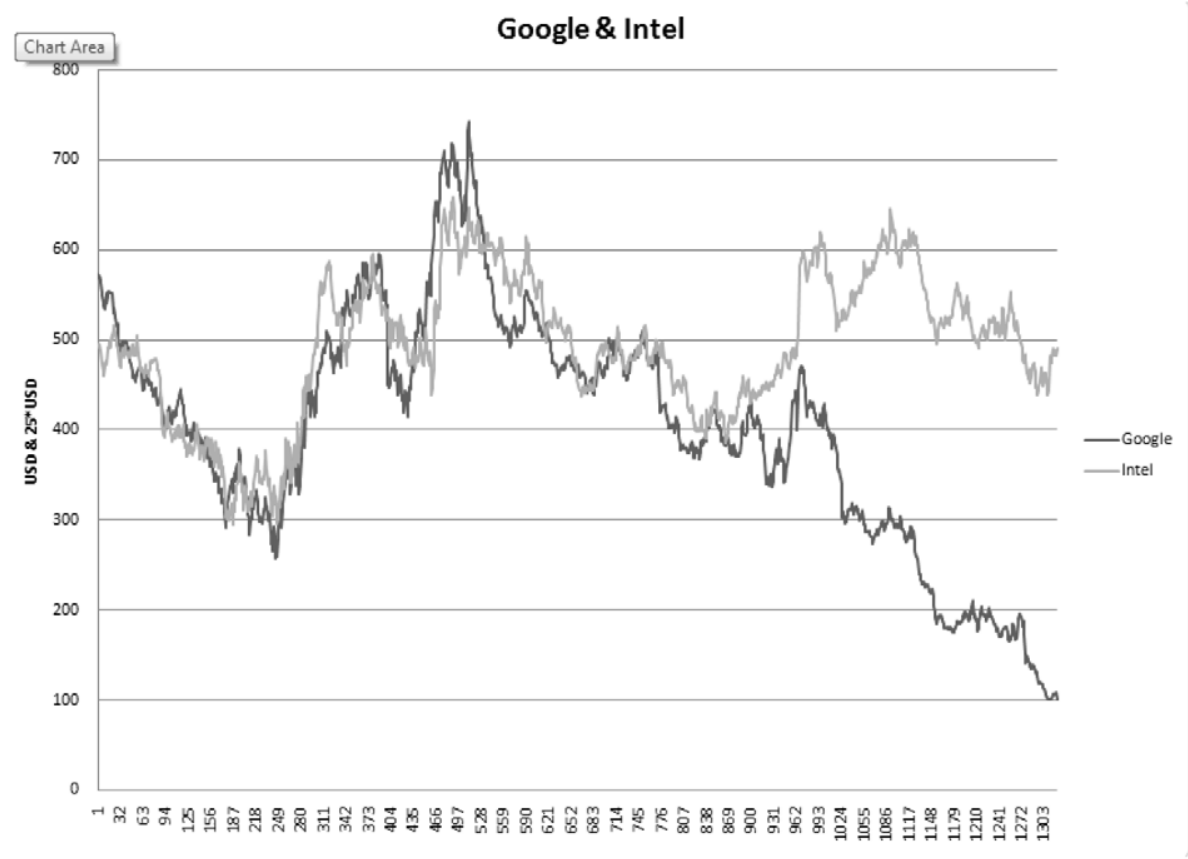

Fig. 8. Historical stock rates of Google and Intel.

Table 1

The residuals of next-day predictions, the first set, data from 2005-01-01 to 2008-01-01, 500 days for training, 250 days for predictions

\begin{tabular}{lccrc}
\hline Asset & AR-ABS $(1) 1$ & AR-ABS $\left(p_{\text {opt }}\right)$ & $p_{\text {opt }}$ & RW \\
\hline Audusd & 0.004525 & 0.004521 & 3 & 0.00453 \\
Brentcrudeoil & 0.9676 & 0.9656 & 17 & 0.97 \\
Ccocoa & 22.572 & 22.572 & 1 & 22.572 \\
Coffee & 1.2863 & 1.2712 & 12 & 1.28 \\
Eurodollar & 0.049286 & 0.04926 & 19 & 0.0493 \\
Kospi & 2.5672 & 2.5536 & 16 & 2.59 \\
Leanhogs & 0.6798 & 0.6797 & 2 & 0.68 \\
Random & 0.7654 & 0.7654 & 1 & 0.765 \\
Tnote5y & 0.1987 & 0.1986 & 5 & 0.2 \\
\hline
\end{tabular}

Different assets are quoted in different currencies. Thus, some numbers are large. For example, the 'kospi' data are quoted in South Korean currency Won. Series from all the major sectors are considered: energy (brentcrudeoil), commodities (cocoa, coffee, leanhogs), currency exchange (audusd), interest rates (eurodollar), equity indexes (kospi), and bonds (tnote5y). 
Table 2

The list of the second set

\begin{tabular}{llll}
\hline Sector & Name & Time & Short name \\
\hline Hydrology & Amazon & $1928-1992$ & Amazon \\
IT & Intel Corporation & $2007.01 .01-2008.12 .31$ & Intc \\
Food industry & Kraft Foods Inc. & $2007.01 .01-2008.12 .31$ & Kft \\
Mutual funds & Templeton Global Bond A & $2007.01 .01-2008.12 .31$ & Tpinx \\
Raw materials & United States Oil & $2007.01 .01-2008.12 .31$ & Uso \\
Currency & Euro-Dollar & $2007.01 .01-2008.12 .31$ & Eurusd \\
Simulation & Virtual Stock Exchange 1 & & Usegm1 \\
Simulation & Virtual Stock Exchange 2 & & Usegm2 \\
\hline
\end{tabular}

Table 3

The residuals of predictions, the second set, 338 items for training and 168 for predictions

\begin{tabular}{llrllr}
\hline Asset & AR-ABS $\left(p_{\text {opt }}\right)$ & Matlab(1) & Matlab(2) & Matlab(9) & \multicolumn{1}{c}{ RW } \\
\hline Amazon & 5.983 & 14.064 & 6.793 & 6.287 & 14.433 \\
Eurusd & 0.395 & 0.416 & 0.451 & 0.503 & 0.395 \\
Intc & 3.141 & 3.391 & 3.095 & 3.172 & 3.078 \\
Kft & 1.439 & 1.429 & 1.442 & 1.466 & 1.437 \\
Tpinx & 0.544 & 9.546 & 0.565 & 0.588 & 0.532 \\
Uso & 3.305 & 3.532 & 3.486 & 3.898 & 3.240 \\
Usegm1 & 1.471 & 1.499 & 1.641 & 1.554 & 1.474 \\
Usegm2 & 3.635 & 3.622 & 3.699 & 3.734 & 3.606 \\
\hline
\end{tabular}

Table 1 shows that the best results were obtained using RW in the simulated Wiener process (as expected) and in time series of cocoa futures prices. Residuals are defined as mean absolute deviation to represent investors which assume a linear utility function. Simulation of the Wiener process has been repeated for 10 times and $p=1$ was always optimal. In the time series of seven other assets, the best results were provided by the $\operatorname{AR}-\operatorname{ABS}(p)$ models of order $p$ with the optimized order $p=p_{\mathrm{opt}}>1$. This indicates that in most cases asset holders are not playing strategies, corresponding to the Wiener model. An interesting exception is futures prices of cocoa. A possible explanation is that the cocoa market is controlled by a few major players who are using buying-selling strategies close to the Nash equilibrium. The situation is different in the remaining seven markets, where the prices depend on the actions of many players. Apparently most of them are looking for greater current profits and are not following equilibrium strategies.

For comparison, Tables 2 and 3 show the results of different time series, using different prediction methods. Here hydrology data are presented in addition to the financial ones. The residuals of predictions are presented as the ratio of the root mean squared error (RMSE) to the sample mean, the sources of data were (rivdis, 2009; Historical quotes, 2009; Fxhistory, 2009). 
To illustrate the influence of the "memory" parameter $p$, three versions of ANN predictions are given: $\operatorname{Matlab}(1)$ means $p=1$, Matlab(2) is for $p=2$, and Matlab(9) means $p=9$. As expected, the best memory for hydrology time series was $p^{*}=9$. The financial data show different results. For eurusd, kft, and tpinx $p^{*}=1$, for intc and uso $p^{*}=2$. For both examples usegm 1 and usegm 2 of simulated time series the optimal $p^{*}=1$.

The $\operatorname{AR}-\operatorname{ABS}(p)$ model optimizes the parameter $p$ automatically and provides the best results for 'amazon', 'eurusd', and 'usegm1' data sets. For 'intc', 'kft', 'tpinx', 'uso', and 'usegm2' data sets, the Wiener model was the best. However, for financial data the differences between RW and $\operatorname{AR}-\operatorname{ABS}(p)$ were not significant statistically. For hydrology time series, $\operatorname{AR}-\operatorname{ABS}(p)$ provided almost three times better results.

Some historical financial time series of 1997 were considered, in addition to relatively recent data, to illustrate the market behavior under more stable financial conditions.

The difference of average prediction errors of ARMA and RW models can be regarded as some parameter of "ARMA-unpredictability" of the data. It means that the time series are not predictable by the ARMA model if the difference is zero or negative. Table 4 shows the difference between the mean square deviations of ARMA and RW models.

The table uses four data sets

- exchange rates of $\mathrm{DM} / \$, \$ / £, \mathrm{Yen} / \$$, and $\mathrm{Fr} / \$$,

- closing rates of AT\&T, Intel Co., and Hermis Bank stocks,

- index of the London Stock Exchange,

- call rates of a call center.

In Table 4, the symbol MeanARMA denotes average prediction errors of the ARMA model. The symbol VarArma means the variance of ARMA predictions. The symbol DeltaARMA\% denotes the relation (RW-ARMA)/RW in percentages. Here RW defines average errors of the Random Walk. DeltaARMA\% $>0$ means that the ARMA model predicts better.

The data are divided into three equal parts: The first part is to estimate the parameters $a$ and $b$ of the ARMA model using fixed numbers $p$ and $q$.

The best values of $p$ and $q$ are defined using the second part of data.

Table 4

The average "next-day" prediction results of ARMA and RW models

\begin{tabular}{|c|c|c|c|}
\hline Data & DeltaARMA\% & MeanARMA & VarARMA \\
\hline$\$ /(£)$ & $-1.779090 e-01$ & $1.293609 e+00$ & $8.454827 e-02$ \\
\hline $\mathrm{DM} / \$$ & $-1.191 e-02$ & $1.092 e-01$ & $9.985 e-02$ \\
\hline Yen $/ \$$ & $-1.086 e+00$ & $6.369 e+00$ & $6.446505 e+00$ \\
\hline $\mathrm{Fr} / \$$ & $-3.029 e-01$ & $4.285 e-01$ & $3.395 e-01$ \\
\hline AT\&T & $-1.375 e+00$ & $4.554 e+00$ & $3.621 e+00$ \\
\hline Intel Co & $+2.814 e-01$ & $2.052 e+01$ & $1.936 e+00$ \\
\hline Hermis Bank & $-4.280 e+01$ & $2.374 e+01$ & $1.998 e+01$ \\
\hline London Stock Exchange & $-5.107 e-01$ & $2.751 e+02$ & $2.346 e+01$ \\
\hline Call Center & $+3.076 e+01$ & $8.453 e+02$ & $7.111 e+02$ \\
\hline
\end{tabular}


The third part is to compare the ARMA and RW models. The table shows the comparison results. Table 4 shows that the ARMA model predicts all the financial data no better than RW. However, the observed deviations between the RW and ARMA models of financial data are too small for statistical conclusions. The results are different for the next-day call rate predictions. Here ARMA predicts call rates thirty one percent better than RW. That is a statistically significant difference. Table 3 shows that, in predicting Amazon river discharge, the residual of the AR-ABS model is almost three times smaller comparing with RW.

No formal experimental design and sophisticated statistical techniques were used in this paper, since the USEGM model is designed as a tool of individual on-line experimentation for graduate studies and scientific collaboration.

\section{Software of the Stock Exchange Game Model}

The stock exchange game model is a part of the general on-line system for graduate studies and scientific collaboration (Mockus, 2006; Mockus, 2003).

The main web site (last modified December, 2011) is at:

http: //mockus.org/optimum.

The mirror sites are at:

http://prof.if.ktu.lt jonas.mockus,

http: //optimum2.mii.lt,

http://kopustas.elen.ktu.1t jmockus,

Examples are in the form of Java applets and can be started by any browser with Java support (assuming that both Java and Javascript are enabled). Applets were compiled by java1.6 so they may not work correctly using lesser versions of Java.

The common feature of examples is that all of them are solved using optimization techniques. Three versions of USEGM are in the section "Global Optimization", subsection "Stock-Exchange Model", subsubsection "Nash Equilibrium, Examples of Global Optimization in the Simplest Stock Exchange Model".

GMJ1 is the reference to prototype of the stock exchange model.

The reference to the version of SEGM that represents up to eight major investors and eight stocks is this:

'GMJ2 stable version, up to 8 customers and 8 stocks with user 'Soros', ,\#1'.

To start applets directly by the 'appletviewer' command (without a web browser), the tt of this version can be used. The updated USEGM model 'STOCK-2' is on the web and can be started using corresponding URL, for example: http : mockus . org / opt i mum/ igor/contigor.html ${ }^{10}$.

In other synchronized servers, the URL should be changed accordingly.

Statistical simulation of USEGM is a time consuming process if $I$ and $J$ are large. The large computing time limits the possibilities of completely automatic optimization. Thus, a multi-processor version is under development. Now the software works up to

\footnotetext{
${ }^{10}$ To make correct reference this URL may be entered manually.
} 
$I=J=8$. In a multi-processor system, the number of major players $I$ will be defined by the number of processors.

In the Internet environment, we need platform-independent languages for running the software on remote computers. Java is more efficient for scientific calculations among such languages. Java applets provide a unique possibility for student-teacher interactions. Students can run the programs remotely and teachers can test students' results on-line.

\section{Concluding Remarks}

The Game Theory is a suitable framework to model financial markets because the future market price of financial assets depends on predictions (and subsequent actions) of the market participants with conflicting interests.

The idea that a financial market is a "casino" game was expressed in Keynes (1936, 2007). In Krugman (2000, 2008, 2009), the unpredictability of asset prices is explained by the irrational behavior of participants.

According to the models of this paper, the seemingly irrational behavior of market participants can be considered as rational under the specific conditions of decision making and the available information. From this standpoint, the differences between the efficient market theory (Fama, 1995), assuming the rational behavior of market players and theories based on the irrational behavior (Krugman, 2000, 2008, 2009) are not so significant.

The proposed financial market model USEGM is designed as a tool for simulating the market processes in response to different changes of market parameters and for estimating the expected profits of different prediction methods using the virtual and historical data. Convenient user interactions are provided by implementing the model as a Java applet and publishing it in an open web-site (Mockus, 2007).

A simple Stock Exchange Game Model (SEGM) was introduced in Mockus (2003, 2010), Mockus and Raudys (2010) to simulate the behavior of several stockholders using fixed buying-selling margins at fixed bank yield. In this paper, an extended model USEGM is proposed. The advantage of USEGM is application to strategies that define buying-selling margins and bank haircuts dynamically. That enables us to simulate market illiquidity that is an important feature of the present financial crisis (Allen, 2008). In addition, USEGM includes the transaction costs, what helps to reflect the reality better. To represent users preferring linear utility functions, USEGM adds the AR-ABS $(p)$ autoregression model minimizing the absolute values. The traditional $\mathrm{AR}(p)$ model minimizing least square deviations reflects risk aversion.

While USEGM may be too simplistic for practical forecasting, it can serve as a useful tool for studies of market behavior by presenting an easy way of simulating different scenarios of player strategies. For example, simulations can explain stock market reaction to deliberately set non-NE strategies of a major stockholder, such as manipulation of asset prices, designed to lower their value.

We have compared the RW model with eighteen actual financial time series and found the results to be close to the Nash equilibrium in some cases. A possible explanation of 
the differences is that major players are not following NE strategies. Some similarity of the results obtained using the simple SEGM model and real data indicates that the approach, based on the assumption of optimal behavior by market participants, may be suitable and useful as a first approximation in the studies of real financial markets. In addition, USEGM can be applied to compare potential profit which can be obtained by various prediction models using historical data.

Using the USEGM simulation, one may notice that a simplistic prediction of future trends is a reason of financial instability. This way USEGM helps students of business informatics to understand better financial disasters that we are witnessing at present.

\section{References}

Abreu, D., Brunnermeier, M. (2003). Bubbles and crashes. Econometrica, 71, 173-204.

Allen, F. (2008). Market illiquidity and financial instability. Technical report. In: Federal Reserve Academic Consultants Meeting on Financial Stability and the Linkages Between the Financial and Real Sectors.

Allen, F., Gale, D. (2007). Understanding Financial Crises. Oxford University Press, Oxford.

Arthanari, T, Dodge, Y. (1993). Mathematical Programming in Statistics. Wiley, New York.

Bernanke, B. (1983). Nonmonetary effects of the financial crisis in the propagation of the great depression. American Economic Review, 73, 257-276.

Bernanke, B. (2005). Essays on the Great Depression. Princeton University Press, Princeton.

Brunnermeier, M.K. (2007). Optimal beliefs, asset prices, and the preference for skewed returns. Technical report, National Bureau of Economic Research, 1050, Massachusetts Avenue, Cambridge, MA 02138.

Brunnermeier, M. (2009). Deciphering the 2007-2008 liquidity and credit crunch. Journal of Economic Perspectives, 23, 77-100.

Brunnermeier, M., Nagel, S. (2004). Hedge funds and the technology bubble. Journal of Finance, 59, 2013 2040.

Brunnermeier, M.K., Julliard, C. (2006). Money illusion and housing frenzies. Technical report, National Bureau of Economic Research, 1050 Massachusetts Avenue, Cambridge, MA 02138.

Brunnermeier, M.K., Nagel, S. (2006). Do wealth fluctuations generate time-varying risk aversion? microevidence on individuals' asset allocation. Technical report, National Bureau of Economic Research, 1050 Massachusetts Avenue, Cambridge, MA 02138.

Brunnermeier, M.K., Pedersen, L.H. (2007). Market liquidity and funding liquidity. Technical report, National Bureau of Economic Research, 1050 Massachusetts Avenue, Cambridge, MA 02138.

Brunnermeier, M.K., Yogo, M. (2009). A note on liquidity risk management. Technical report, National Bureau of Economic Research, 1050 Massachusetts Avenue, Cambridge, MA 02138.

Brunnermeier, M.K., Nagel, S., Pedersen, L.H. (2008). Carry trades and currency crashes. Technical report, National Bureau of Economic Research, 1050 Massachusetts Avenue, Cambridge, MA 02138.

Darley, V., Outkin, A.V. (2007). A NASDAQ market simulation insights on a major market from the science of complex adaptive systems. World Scientific, Hackensack.

Debreu, G. (1982). Existence of competitive equilibrium. In: Handbook of Mathematical Economics, 2. Elsevier, Amsterdam.

Dzemyda, G., Sakalauskas, L. (2011). Large-scale data analysis using heuristic methods. Informatica, 22, 1-10.

Fama, E.F. (1995). Random walks in stock market price. Financial Analysts Journal, 1, 75-80.

(2009). Fxhistory: historical currency exchange rates. http: / /www . oanda . com/ convert/ fxhistory.

Greenspan, A. (2009). Market crisis 'will happen again'.

http://news.bbc.co.uk/go/pr/fr/-/2/hi/business/8244600.stm.

Historical quotes (2009). http: / / finance. yahoo. com/.

Keynes, J.M. (1936, 2007). The General Theory of Employment, Interest and Money. Macmillan, London.

Krugman, P. (Ed.) (2000). Currency crises. In: National Bureau of Economic Research Conference Report.

The University of Chicago Press, Chicago.

Krugman, P. (2008). The Return of Depression Economics and the Crisis of 2008. Norton \& Co, New York. 
Krugman. P. (2009). How did economists get it so wrong? The New York Times, September 2.

Mockus, J. (2003). Stock exchange game model as an example for graduate level distance studies. Computer Applications in Engineering Education, 10, 229-237.

Mockus, J. (2006). Investigation of examples of e-education environment for scientific collaboration and distance graduate studies, Part 1. Informatica, 17, 259-278.

Mockus, J. (2007). http: / / optimum2 .mii.1t/.

Mockus, J. (2010). On simulation of optimal strategies and Nash equilibrium in the financial market context. Journal of Global Optimization, 48, 129-143.

Mockus, J., Raudys, A. (2010). $n$ the efficient-market hypothesis and stock exchange game model. Expert Systems with Applications, 37, 5673-5681.

Mockus, J., Eddy, W., Mockus, A., Mockus, L., Reklaitis, G. (1997). Bayesian Heuristic Approach to Discrete and Global Optimization. Kluwer Academic, Dordrecht.

Nash, J. (1951). Noncooperative games. Annals of Mathematics, 54, 286-295.

Plagge, A. (2007). Defying the random walk. PhD thesis, University of Rochester, Department of Political Science, Rochester, NY 14627, USA.

Ramanauskas, T., Rutkauskas, A. (2009). Building an artificial stock market populated by reinforcementlearning agents. Lietuvos Bankas, Working paper, Series 6.

The global river discharge database (rivdis v1.1) (2009). http: / / www . rivdis.sr. unh. edu/.

Strongin, R., Sergeyev, Y. (2000). Global Optimization with Non-Convex Constraints: Sequential and Parallel Algorithms. Kluwer Academic, Dordrecht.

J. Mockus graduated Kaunas University of Technology, Lithuania, in 1952. He got his doctor habilitus degree at the Institute of Computers and Automation, Latvia, in 1967. He is a principal researcher of System Analysis Department, Vilnius University, Institute of Mathematics and Informatics and professor of Kaunas University of Technology. His research interests include global and discrete optimization.

\section{Apie Nash'o pusiausvyros modeliavimą akcijų biržos kontekste} Jonas MOCKUS

Paprasčiausias akcijų biržos modelis (SEGM) buvo pasiūlytas (Mockus, 2003, 2010; Mockus ir Raudys, 2010) kelių akcininkų elgesio aprašymui, naudojančiu pastovius pirkimo-pardavimos slenksčius ir banko palūkanas. Straipsnyje siūlomas sudėtingesnis modelis USEGM. Jo privalumas yra Nash'o pusiausvyros (NE) pritaikymas, nustatatant kintančius laike pirkimo-pardavimo slenksčius ir banku palūkanas. Tai suteikia galimybe modeliuoti bloga rinkos likviduma, kuris buvo charakteringas finansu rinkos krizei. Be to, USEGM ịvertina finansinių operaciju kaštus, kurie neišvengiami praktikoje. Siekiant geriau modeliuoti akcininkus kurie orientuojasi ị tiesines naudingumo funkcijas, USEGM papildomai realizuoja $\left.\operatorname{AR} \operatorname{ABS}^{\prime} p\right)$ autoregresijos modeli, kuris minimizuoja absoliutinius nukrypimus. Tradicinis $\operatorname{AR}(p)$ modelis minimizuoja kvadratinius nukrypimus.

Formalus NE pritaikymas finansų rinkos dalyvių elgesiui modeliuoti yra nauja šiu modeliu ypatybė. Allen (2008), Brunnermeier (2009), Brunnermeier ir Yogo (2009) darbuose pusiausvyros idèjos buvo taikomos nagrinejjant pasiūlos-paklausos balansą.

Rinkos prognozavimas nèra USEGM modelio tikslas. Modelis skirtas aprašyti finansiniu eilučiu priklausomybę nuo akcininkų naudojamo prognozavimo metodo bei jụ elgesio. Tuo būdu, „virtuali“ akciju rinka pagrista NE gali būti panaudota tikrinti tradicinę efektyvios rinkos teorija, atžvilgiu nauju ideju, aiškinančiu rinkos procesus neracionaliu rinkos rinkos dalyvių elgesiu. Modelis buvo lyginams su aštuoniolika realių laiko eilučių; daugeliu atvejų rezultatai buvo panašūs. 